\title{
Topical Calcineurin Inhibitor Tacrolimus in Orabase: an Alternative Treatment for Erosive Oral Lichen Planus
}

\author{
MIHAELA PAULA TOADER ${ }^{1,2}$, MADALINA MOCANU ${ }^{2,3 *}$, STEFAN TOADER $^{3 *}$, \\ ROXANA IRINA IANCU ${ }^{3 *}$, TATIANA TARANU ${ }^{1,2}$ \\ ${ }^{1}$ University of Medicine and Pharmacy Grigore T. Popa, Discipline of Dermatology, 16 Universitatii Str., 700115, Iasi, Romania \\ ${ }^{2}$ University C.F. Hospital, Dermatology Clinic, $1^{\text {st }}$ Garabet Ibraileanu Str., 700506, Iasi, Romania \\ ${ }^{3}$ University of Medicine and Pharmacy Grigore T. Popa, Discipline of Pathophysiology, 16 Universitatii Str., 700115, Iasi, Romania
}

\begin{abstract}
Tacrolimus, a macrolide with immunosuppressive properties through the inhibition of Tlymphocyte activation, was approved as a second line topical treatment for atopic dermatitis, but has been largely used with beneficial effects in other dermatological conditions that involve a disregulation of the cellular immune response. Oral lichen planus is a T-cell-mediated autoimmune disease in which autocytotoxic $C D 8^{+} T$ cells trigger apoptosis of oral epithelial cells. Our study aimed to analyze the clinical efficacy of tacrolimus $0.03 \%$ and $0.1 \%$ in orabase as monotherapy on oral erosive lesions of lichen planus, in a group of 20 patients consulted in the Dermatology Clinic of the University C.F. Hospital Iasi during a period of five years. Our results show total or partial remission of oral erosive lesions in most patients at 3 months follow-up. However, after treatment discontinuation relapses are common, which is why intermittent use of topical tacrolimus is needed for longer periods to prevent recurrences. Further large scale studies are necessary to establish efficacy and safety profile of prolonged use of tacrolimus on mucosal membranes, as well as the most appropriate vehicle and concentration.
\end{abstract}

Keywords: Tacrolimus, oral lichen planus, oral white lesions, oral erosions, premalignant oral lesions

\section{Introduction}

Tacrolimus, also known as fujimycin or FK 506, is a macrolactam immunomodulator, isolated in 1984 from the fungus Streptomyces tsukubaensis. The empirical formula is $\mathrm{C}_{44} \mathrm{H}_{69} \mathrm{NO}_{12} \cdot \mathrm{H}_{2} \mathrm{O}$, with a formula weight of 822.03 [1]. The structural formula is shown in Figure 1.

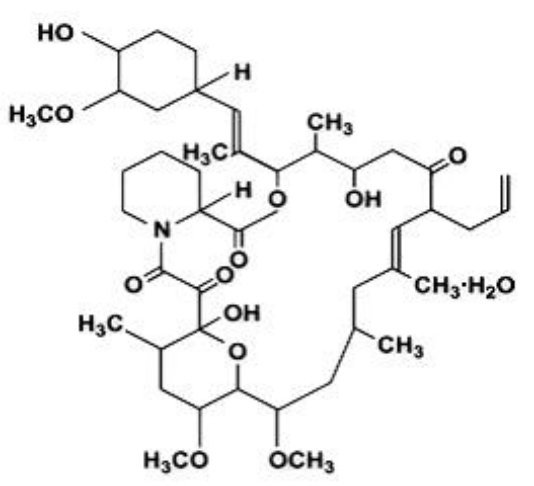

Figure. 1. Tacrolimus structural formula

After entering $\mathrm{T}$ cells, it binds with cytoplasmic immunophilins to form a complex that further binds to calcineurin, leading to a selective inhibition of calcineurin phosphatase activity. This results in a reduced dephosphorylation of the nuclear factor of activated T-cells, which blocks the transcription

\footnotetext{
*email:drmadalinamocanu@yahoo.com,toaderstefan@gmail.com,rox_iancu@yahoo.com
} 
of several cytokine genes, such as interleukin (IL) 2 , IL-3, IL-4, interferon- $\gamma$ (IFN- $\gamma$ ) and tumour necrosis factor (TNF)- $\alpha$. Tacrolimus has been shown to have immunomodulatory effects through several mechanisms: it inhibits the production of T-helper 1(Th1) and Th2 cytokines, as well as T cell activation/maturation; it inhibits mast cell adhesion and release of mediators from mast cells and basophils; it reduces expression of IL-8 receptors on keratinocytes and of FCERI on Langerhans' cells $[1,2]$. Topical tacrolimus was reported to decrease cytokine mRNA levels of IL-1 $\alpha$, IL-1 $\beta$ and macrophage inflammatory protein (MIP)-2. It was approved as a second line topical treatment for atopic dermatitis, but it has been extensively utilized, with reported beneficial effects, in several dermatoses in which there is impaired cellular immune response, such as lichen planus, lichen sclerosus, psoriasis (facial lesions and inverse psoriasis with severe impact on patient's quality of life), lupus erythematosus, localized scleroderma, bullous and cicatricial pemphigoid, rosacea, seborrheic dermatitis, vitiligo, chronic actinic dermatitis, granuloma annulare, pyoderma gangrenosum, progressive purpuric dermatosis [1-5].

Oral lichen planus (OLP) is a chronic inflammatory disorder due to a T-cell mediated autoimmune response in which auto-cytotoxic $\mathrm{CD} 8+\mathrm{T}$ cells trigger apoptosis of the basal cells of the oral epithelium, affecting 1-3\% of the population, with a higher prevalence in women (women to men ratio 1.4:1) [6, 7]. Clinical manifestations are variable and most commonly present as white striations (Wickham striae), white papules, white plaques, erythema, mucosal atrophy, erosions, or pigmented patches, symmetrically distributed on the buccal mucosa, tongue, and gingivae, although other oral sites are occasionally involved. Clinical course is usually chronic, over several years, with a reported risk of malignant transformation of $0.04-1.74 \%$, especially in erosive forms and in female patients [8]. Topical corticosteroids are the mainstay of treatment in oral lichen planus. Other therapies, for recalcitrant oral lesions, include cyclosporin, hydroxychloroquine, azathioprine, mycophenolate, dapsone, systemic corticosteroids, topical and systemic retinoids, topical calcineurin inhibitors [6-13].

Up to date there are several studies regarding the efficacy and safety of topical calcineurin inhibitor tacrolimus in the treatment of erosive oral lichen planus, showing promising results, with concentrations of $0.03 \%$ or $0.1 \%$ in different vehicles (ointment, lipid-loaded microspheres or mouth washes) and different treatment regimens [11-15]. However, topical tacrolimus is not widely used in the treatment of OLP in our country.

Considering the long, relapsing course of erosive OLP, with severe impact on the patients' quality of life, and the challenges related to prolonged use of topical or intralesional corticosteroids due to drug tolerance, atrophy, secondary infection or adrenal insufficiency, we aimed to determine if topical tacrolimus is a potentially effective alternative treatment, based on the published foreign literature. For this purpose we used topical tacrolimus $0.03 \%$ and $0.1 \%$ in orabase, a vehicle adapted for the mucosal membrane, not included in any of the previously published studies. Orabase is an emollient paste containing gelatin, pectin, carboxymethylcellulose in plasticized hydrocarbon gel, that adheres to the moist oral mucosal membrane and allows slow release of the active principle at the site of application. Moreover, it creates a film coating mucosal erosions, protecting the wound from infection and alleviating discomfort.

\section{Materials and methods}

We performed a retrospective observational study on a cohort of 20 patients diagnosed clinically and histopathologically with erosive OLP, with or without cutaneous lesions, consulted in the Dermatology Clinic of the University C.F. Hospital Iasi, during August 2014 and August 2019 and treated with topical tacrolimus in orabase as monotherapy. Inclusion criteria in the study were: age over 18 years (to obtain informed consent given the off-label use of the treatment) and fulfilment of World Health Organisation clinical and histopathological diagnostic criteria for erosive OLP. Patients with dysplastic leukokeratosis of the oral mucosa, oral candidiasis or lichenoid lesions of the oral mucosa adjacent to a dental restauration material were excluded, due to the potential adverse effects of tacrolimus. Previous treatments with corticosteroids, retinoids or immunosupressants were considered 
exclusion criteria, in order to assess the efficacy of tacrolimus, not influenced by other therapies. The research was conducted in accordance with the bioethical norms provided by EU legislation. Demographic data, information regarding clinical aspect, symptoms, paraclinical results and therapeutic regimen were obtained from patients' charts. Patients were then divided into two subgroups - one subgroup of patients treated with topical tacrolimus $0.03 \%$ in orabase $(\mathrm{n}=13$ patients) and one subgroup treated with tacrolimus $0.1 \%$ in orabase ( $\mathrm{n}=7$ patients). Assessment of treatment efficacy was made taking into consideration the following criteria: pain, functional impairment, erythema, epithelization of erosive lesions, attenuation of white lesions, occurrence of new erosive lesions. The degree of pain and functional impairment was evaluated by the patient and recorded in patient's chart. Subsequently pain was graded from I to V according to severity, V being the most severe, while functional impairment was graded as 1 (no or mild discomfort in speaking and/or eating), 2 (moderate discomfort in eating, drinking and speaking) or 3 (severe discomfort with impossibility of feeding). Patients' photographs from the archive of the Dermatology Clinic were reexamined to evaluate disease evolution and treatment efficacy. Evaluation of clinical signs such as erythema, white lesions (reticular, papular, plaque-type), erosions' size was made by comparing photographs of the patient taken during each presentation (initial and follow-up). Most of the patients (16 cases $-80 \%$ ) were reevaluated every 3 months for one year. Four patients were only monitored for 6 months.

\section{Results and discussions}

Erosive OLP was more prevalent in females $(18$ patients $-90 \%)$ and in the $5^{\text {th }}$ decade of life (5 patients $-25 \%$ ) (Figure 2).

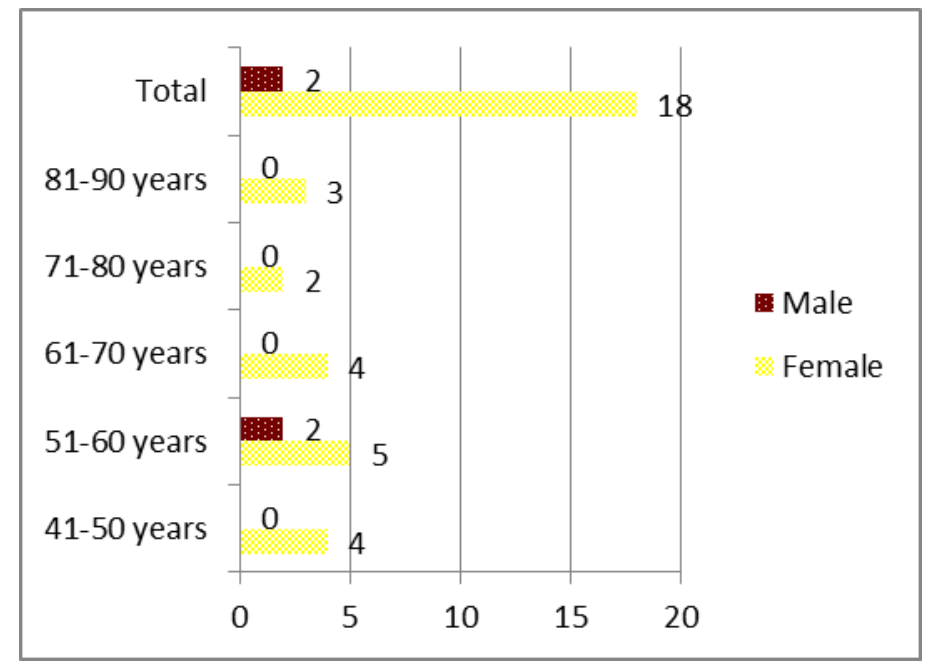

Figure 2. Distribution of erosive OLP cases according to age group and gender

Subgroup one consisted of 13 female patients (65\%) treated with topical tacrolimus $0.03 \%$ in orabase and the second subgroup consisted of 7 patients (35\%), 2 male patients and 5 female patients, treated with topical tacrolimus $0.1 \%$ in orabase (Figure 3). Treatment regimen in both subgroups consisted in twice daily application, with progressive decrease of applications in relation to the clinical evolution. 




Figure 3. Distribution of cases according to gender and treatment regimen

The evolution of the clinical parameters during treatment in the two subgroups is presented in Table 1.

Table 1. Evolution of clinical parameters during treatment in the two subgroups

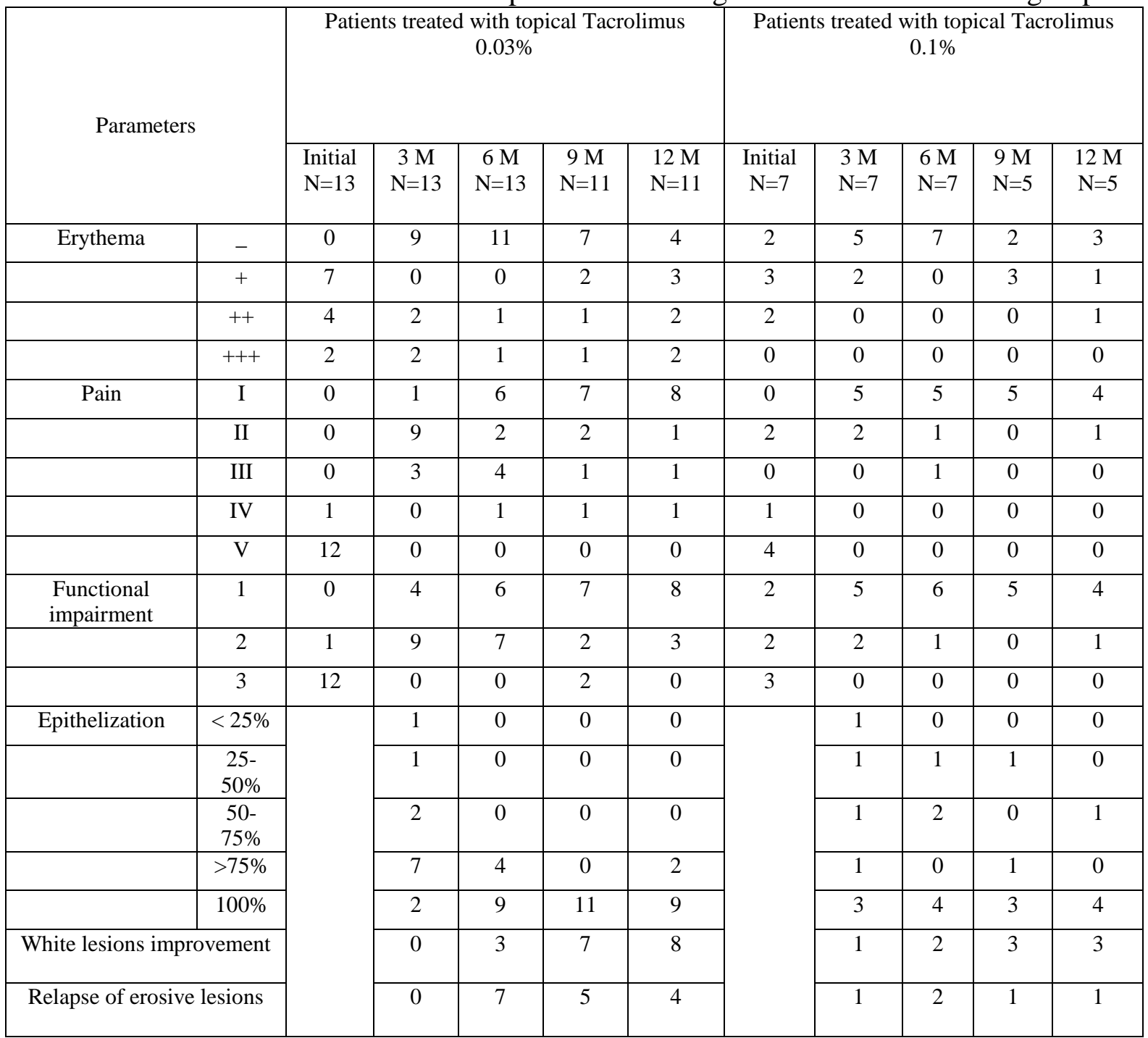

In the subgroup treated with topical tacrolimus $0.03 \%$ in orabase erythema showed significant improvement in the first 3 months, 9 of the 13 patients $(69.23 \%)$ experiencing complete resolution. Pain and functional impairment were also significantly diminished in the first 3 months, 9 patients $(69.23 \%)$ reaching a pain score II and one patient experiencing complete pain relief, with constant 
improvement over the next 9 months, with 8 patients $(61.53 \%)$ describing complete pain relief. Complete epithelization of the erosive lesions was noted in 11 of the 13 patients at 9 months $(84.61 \%)$, even though relapse occurred after 3 months in 7 patients (53.84\%). Discrete improvement of white lesions was also noted, particularly in reticular clinical forms, in 8 patients $(61.53 \%)$ over 12 months of treatment.

In the subgroup treated with topical tacrolimus $0.1 \%$ in orabase erythema showed complete resolution in all patients after 6 months, with recurrence at months 9 (2 patients $-28.57 \%)$ and $12(3$ patients $-42.85 \%$ ). Pain and functional impairment improved significantly after 3 months of treatment (5 of 7 patients $-71.42 \%$ experienced complete resolution). Partial or complete epithelization of erosive lesions occurred after 3 months of treatment in 5 patients $(71.42 \%)$ (Figure 4 ) and continued to improve by month 6 (Figure 5). Relapse occurred in one patient after 3 months, in 2 patients after 6 months. Other patients experienced reoccurrence of erosive lesions at month 9 (1 patient) and month 12 (1 patient).

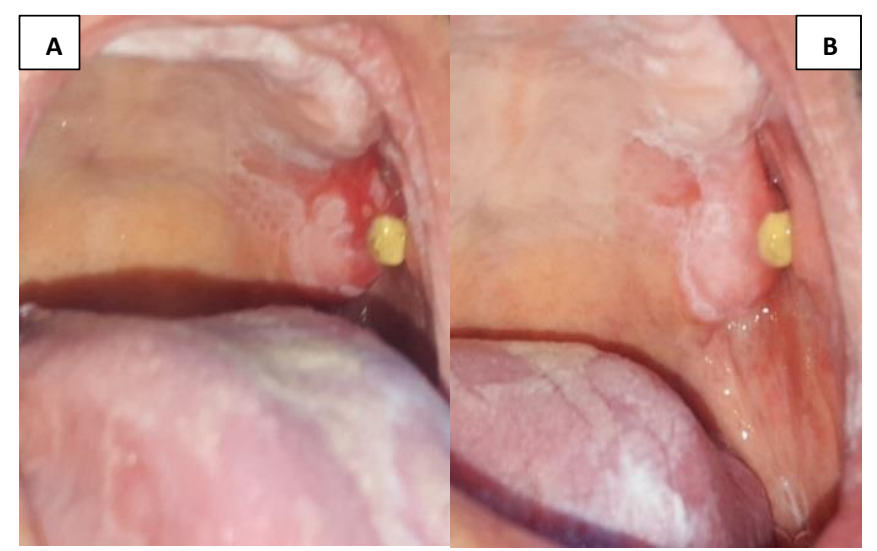

Figure 4. Erosive, reticular and plaque-type oral lichen planus in a 55 years old male patient. A. First presentation with irregular, painful erosion surrounded by white plaque-type lesions with a reticular appearance. B. Follow-up at 3 months of treatment with topical tacrolimus $0.1 \%$

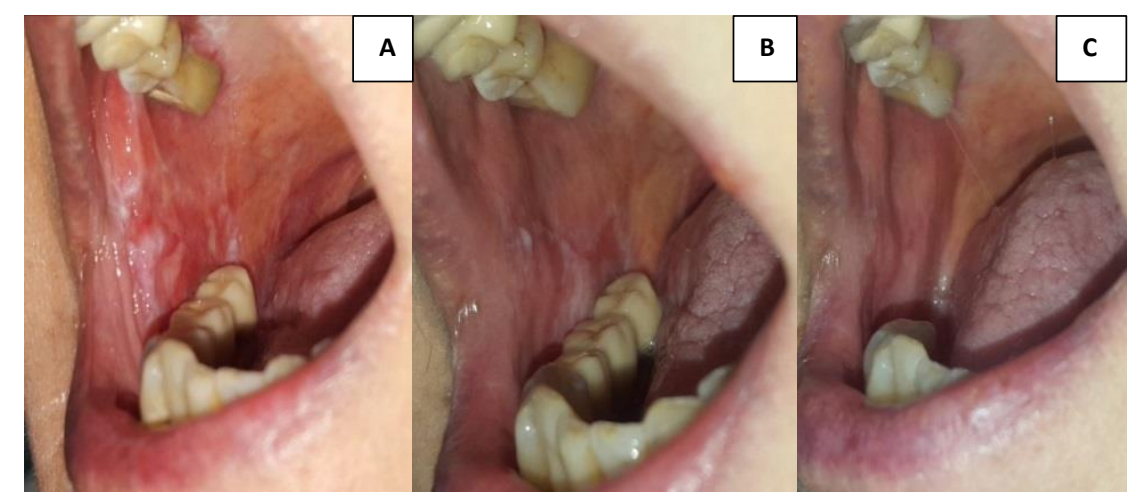

Figure 5. Erosive, papular and reticular oral lichen planus in a 48 years old female patient at initial presentation (A), 3 months follow-up (B) and 6 months follow-up (C)

The first report of a possible use of topical tacrolimus ointment in the treatment of erosive mucosal lichen planus was an observational series of six patients with severe mucosal lichen planus who were treated with $0.1 \%$ tacrolimus ointment twice daily. Authors reported a substantial improvement in 3 cases and complete resolution in the other 3 patients after 4 weeks. However, recurrences were noted in 5 patients after treatment discontinuation in 3 to 8 weeks [11]. Several other reports of patients with 
OLP treated with topical tacrolimus showed similar findings, either using topical $0.1 \%$ tacrolimus ointment or topical tacrolimus in the form of a mouthwash $(0.1 \mathrm{mg}$ per $100 \mathrm{~mL}$ of water). In larger studies with a more extended follow-up period, patients with symptomatic erosive or ulcerative OLP recalcitrant to topical glucocorticoids were evaluated after being treated with $0.1 \%$ topical tacrolimus twice daily for one to two years, with significant partial or complete resolution after 2 months. However, continued intermittent therapy was required to maintain remission $[12,13]$.

Our study shows more than $75 \%$ epithelization after 3 months $(69.23 \%$ of patients treated with tacrolimus $0.03 \%$ and $57.14 \%$ of patients treated with tacrolimus $0.1 \%$ ). Relapses at 3 months followup were only present in one patient treated with topical tacrolimus $0.1 \%$. However, at 6 months follow-up relapses were seen in $53.84 \%$ of patients treated with $0.03 \%$ topical tacrolimus as opposed to only $28.57 \%$ in the group treated with $0.1 \%$ topical tacrolimus. Pain and functional impairment improved significantly after 3 months in both subgroups $(76.92 \%$ of patients treated with $0.03 \%$ topical tacrolimus experienced significant improvement in pain score, while $71.42 \%$ in patients treated with $0.1 \%$ topical tacrolimus experienced complete resolution of symptoms). Our results suggest a lower concentration of tacrolimus in orabase may be used to obtain clinical improvement, but treatment must be applied intermittently for longer than 3 months in order to maintain remission. However, our study group is small, the two subgroups are non-homogenous, making the comparison between them difficult to interpret as significant.

As opposed to topical glucocorticosteroids, which seem to delay wound healing in laboratory animals, tacrolimus appears to increase epithelization, proliferation of fibroblasts and collagen synthesis, making it a good option for long-term treatment, as it does not induce atrophy either [16]. However, a comparative clinical study on the efficacy of topical tacrolimus $0.1 \%$ ointment versus triamcinolone acetonide over a follow-up period of 6 months showed no significant differences in efficacy or adverse events [15].

Currently there are limited data in the literature regarding the risk of systemic absorbtion of topical tacrolimus when applied to mucosal membranes and on the possible adverse effects due to a potentially higher serum concentrations of the drug. One study found systemic absorbtion of tacrolimus in two out of eleven patients with OLP treated with topical $0.01 \%$ tacrolimus, not surpassing the therapeutic levels of 5-20ng/L, with no adverse effects at 6 months follow-up [15]. Percutaneous application leads to an absorbtion by intact skin at low rates of $3.1 \mathrm{ng} / \mathrm{cm}^{2}$ per hour for $0.03 \%, 4.9 \mathrm{ng} / \mathrm{cm}^{2}$ per hour for $0.1 \%$ and $6.8 \mathrm{ng} / \mathrm{cm} 2$ per hour for $0.3 \%$ ointment concentrations, with significantly higher rates in damaged skin, of $40 \mathrm{ng} / \mathrm{cm}^{2}$ per hour. Continuous therapy, with subsequent improvement of skin barrier, leads to a progressively lower absorbtion and fewer adverse systemic effects over the course of treatment, making it possible to administer it to patients with hepatic impairment or undergoing large surgical interventions [10, 17-22]. In our study, apart from a burning sensation when tacrolimus was locally applied on erosive oral lesions, no other adverse effects were reported.

The risk of malignancy is a controversial subject as the prolonged use of calcineurin inhibitors is considered to increase cancer risk [8, 22-25]. The development of squamous cell carcinomas in a patient with oral lichen planus treated with topical tacrolimus was reported in the literature [25]. However, it is difficult to attribute it to the treatment itself, as there is also an increased risk for malignant transformation of oral lichen planus lesions.

There are a few limitations of our research. It is a unicentric study, with a relatively small sample size of patients because topical tacrolimus in orabase is not commonly used for treating erosive OLP in our country. The retrospective nature of our analysis prevented us from finding homogenous study groups for a case-control research and from creating a study design with standardized objective measures to assess therapeutic response. 


\section{Conclusions}

Management of erosive OLP is challenging due to its chronic, relapsing course and limited therapeutic options, mostly due to adverse events in case of prolonged use. Topical tacrolimus in orabase shows promising results, improving both clinical signs and symptoms when applied twice daily, with progressive decrease of applications in relation to the clinical evolution, for 3 months. However, recurrence of the erosive lesions renders it necessary to continue treatment for longer periods. Topical tacrolimus in orabase may be considered as an alternative treatment for erosive OLP, either in monotherapy, or as a corticosteroid sparing agent to maintain remission, with intermittent administration. The specially formulated vehicle that adheres to mucosal moist surface may allow for lower concentrantions of tacrolimus to be used, with beneficial therapeutic effects, similar to higher concentrations, at 3 months follow-up. Further large scale studies with follow-up are needed to establish safety profile and efficacy of topical tacrolimus on mucosal membranes, as well as the most suitable vehicle to use on injured mucosal membranes and the appropriate concentration.

\section{References}

1. MILLIKAN, L.E., Drug Therapy in Dermatology, NY: Marcel Dekkar, Inc., 2004, 161-170.

2. PANHANS-GROSS A, NOVAK N. KRAFT S, BIEBER, T., Human epidermal Langerhans' cells are targets for the immunosuppressive macrolide tacrolimus (FK506), J. Allergy. Clin. Immunol., 107, 2001, 345-352.

3. JOVANOVIĆ, M., GOLUŠIN, Z., Nonsteroidal Topical Immunomodulators in Allergology and Dermatology, BioMed. Research International, 2016, 1-11.

4. PORUMB-ANDRESE, E., VATA, D., POSTOliCA, R., STATESCU, L., STATESCU, C., GRAJDEANU, A.I., PATRASCU, A.I., POPESCU, I.A., GHEUCA SOLOVASTRU, L., Association between personality type, affective distress profile and quality of life in patients with psoriasis vs. patients with cardiovascular disease, Exp. Ther. Med., 18(6), 2019, 4967-4973.

5. STOICA, L.E., VILCEA, A.M., DASCALU, R.C., CIUREA, R.N., DIACONU, R., Schamberg Disease/Progressive Purpuric Dermatosis-Diagnosis and Management Challenges, Rev. Chim., 70(11), 2019, 3961-3963.

6. MITRAN, M.I., NICOLAE, I., ENE, C.D., MITRAN, C.I., MATEI, C., ENE, C., TAMPA, M., GEORGESCU, S.R., Relationship Between Gamma-glutamyl Transpeptidase Activity and Inflammatory Response in Lichen Planus, Rev. Chim., 69(3), 2018, 739-743.

7. POPOVSKA, M., RADOJKOVA-NIKOLOVSKA, V., MINOVSKA, A., AGOP FORNA, D., MURATOVSKA, I., FORNA, N.C., Etiopathogenic Biochemical Mechanism Involved in Oral Lichen Planus, Rev. Chim., 66(11), 2015, 1786-1790.

8. FITZPATRICK, S.G., HIRSCH, S.A., GORDON, S.C., The malignant transformation of oral lichen planus and oral lichenoid lesions: a systematic review, J. Am. Dent. Assoc., 145, 2014, 45-56.

9. DE ROSSI, S.S., CIARROCCA, K., Oral lichen planus and lichenoid mucositis, Dent. Clin. North Am., 58 (2), 2014, 299-313.

10. GUPTA, A.K., ADAMIAK, A., CHOW, M., Tacrolimus: a review of its use for the management of dermatoses, J. Eur. Acad. Dermatol. Venereol., 16, 2002, 100.

11. VENTE, C., REICH, K., RUPPRECHT, R., NEUMANN, C., Erosive mucosal lichen planus: response to topical treatment with tacrolimus, Br. J. Dermatol., 140, 1999, 338-342.

12. HODGSON, T.A., SAHNI, N., KALIAKATSOU, F., BUCHANAN, J.A., PORTER, S.R., Longterm efficacy and safety of topical tacrolimus in the management of ulcerative/erosive oral lichen planus, Eur. J. Dermatol., 13, 2003, 466-470.

13. YANG, H., WU, Y., MA, H., JIANG, L., ZENG, X., DAN, H., ZHOU, Y., CHEN, Q., Possible alternative therapies for oral lichen planus cases refractory to steroid therapies, Oral Surg. Oral Med. Oral Path. Oral Radiol., 121(5), 2016, 496-509.

14. CHUN-LAN, G., JI-ZHI, Z., JIE, Z., HAI-TAO, D., Efficacy of Topical Tacrolimus for Erosive Oral Lichen Planus: A Meta-analysis, Chin. Med. J., 30(4), 2015, 210-217. 
15. SIPONEN, M., HUUSKONEN, L., KALLIO-PULKKINEN, S., NIEMINEN, P., SALO, T., Topical tacrolimus, triamcinolone acetonide, and placebo in oral lichen planus: a pilot randomized controlled trial, Oral Diseases, 23 (5), 2017, 660-668.

16. NAMKOONG, S., CHUNG, J., YOO, J., JUNG, M., GYE, J., KIM, J.S., KIM, J.Y., AHN, S.K., PARK, B.C., KIM, M.H., HONG, S.P., Topical tacrolimus does not negatively impact acute skin wound healing, Exp. Dermatol., 22(5), 2013, 369-371.

17. RUZICKA, T., ASSMANN, T., HOMEY, B., Tacrolimus: The drug for the turn of the millennium?, Arch. Dermatol., 135, 1999, 574.

18. TRIFAN, A.V., STOICA, O., STANCIU, C., COJOCARIU, C., SINGEAP, A.M., GIRLEAN, I., MIFTODE, E.G., Clostridium difficile infection in patients with liver disease: a review, European Journal of Clinical Microbiology \& Infectious Diseases, 34 (12), 2015, 2313-2324.

19. TEODOR, D., JUGANARIU, G., MIFTODE, E.G., Use of Sf-36 Questionnaire in Evaluating the Quality Of Life of Hepatitis C Patients on Antiviral Therapy - Pilot Study, Revista de Cercetare si Interventie Sociala, 44, 2014, 253-265.

20. COMAN, M., CHISCOP, I., MATEI, M.N., GHIBU, L., MIFTODE, E.G., DOROBAT, C., NECHITA, A., EARAR, K., ILIE, M., MOISEI, M., LECA, D., Dynamics of Biochemical Changes in Viral B Virus Hepatitis, Rev. Chim., 66 (12), 2015, 2144-2146.

21. ALEXA, O., PERTEA, M., MALANCEA, R.I., PUHA, B., VELICEASA, B., Our experience in the surgical treatment of acetabular fractures using ,spring plate” technique, Med. Surg. J., 123(2), 2019, 275-281.

22. PERTEA, M., VElEnCiUC, N., GROSU, O., VEliCEASA, B., POROCH, V., LUNCA, S., Reconstruction of heel soft tissue defects using sensate medial plantar flap, J Mind Med Sci.,5(2), 2018, 250-254.

23. NIWA, Y., TERASHIMA, T., SUM, I., Topical application of the immunosuppressant tacrolimus accelerates carcinogenesis in mouse skin, Br. J. Dermatol., 149, 2003, 960-967.

24. SARBU, I., POPA, C., COSTAN, V., BEZNEA, A., TOPOR, G., PLESEA CONDRATOVICI, C., FOTEA, S., The Action Mechanism of Chemical Agents in the Differences Between Oral Pathology and General Pathology, Rev. Chim., 70(12), 2019, 4414-4419.

25. MATTSSON, U., MAGNUSSON, B., JONTELL, M., Squamous cell carcinoma in a patient with oral lichen planus treated with topical application of tacrolimus, Oral Surg. Oral Med. Oral Pathol. Oral Radiol. Endod., 110, 2010, 19-25.

Manuscript received: 03.12.2019 